\title{
Communication
}

Heather Brodie Perry*

\section{Is Access Enough? Interrogating the Influence of Money and Power in Shaping Information}

https://doi.org/10.1515/opis-2020-0003

Received October 28, 2019; accepted February 22, 2020

\begin{abstract}
Access to information encourages innovation and leads to participation in society of individuals. The emergence of Open Access supports the inclusion of all, including the voices of the traditionally marginalized, yet access alone is insufficient to enable consumers to effectively use information. Power structures can influence the information available and silence opposing viewpoints. Industry disinformation can influence viewpoints and shape policy in ways that can be detrimental to individuals and the community. Information consumers may not possess the competence required to navigate the complex information ecosystem to find the accurate, high-quality, resources required to meet their need. Libraries have a role in assisting consumers develop the critical evaluation capabilities essential to the exercise of informed skepticism when evaluating truth claims. Access is essential; however, without the knowledge to determine the quality and validity of information, a consumer can be misled in ways that can cause harm to themselves and society.
\end{abstract}

Keywords: open access; industry funding of scientific research; disinformation; conflict of interest; information literacy

\section{Introduction}

Open Access (OA) offers many potential societal and economic benefits by providing free access to scholarly research and the right to use it and to share it. OA encourages the advancement of scientific innovation to increase knowledge, address problems, and has the potential to transform lives (SPARC, 2019). Access to information is so essential for full participation in society that the United Nations Universal Declaration of Human Rights Article 19 specifically addressed access to information in writing:

Everyone has the right to freedom of opinion and expression; this right includes freedom to hold opinions without interference and to seek, receive, and impart information and ideas through any media and regardless of frontiers. (United Nations, 2018)

However, in a time when the ways in which information is created, disseminated, and accessed are rapidly changing, it has become apparent that access is not the only concern. Access to information has historically been dominated by those with power, money, and resources. In the traditional publishing model, journal subscriptions were available to those who could pay; even public libraries are often limited in the resources they can provide by the wealth of the communities they serve. The traditional journal-publishing model, despite its many flaws, had mechanisms to assist readers in discerning the quality and veracity of the

*Corresponding author, Heather Brodie Perry, Stonehill College, Easton, MA United States, E-mail: hperry@stonehill.edu 
articles they were reading. Peer-review provided some level of quality control, and libraries selected titles that met the needs of the communities they served. Open access provides all users with access to journals of varied quality from predatory journals to high-quality titles. Readers may not have sufficient skill to discern the veracity of the information they are reading. Assisting users in finding accurate materials to fit their needs has been a role that librarians have traditionally filled. Today information seekers can find information without using the library; indeed, some people do not have access to libraries at all, restricting access to only those who can pay. This paper will argue that access to information is a necessary but not a sufficient condition for all persons to fully exercise their agency and fulfill the potential of Open Access. As our models of communicating scholarship change, several questions arise. Whose voices are being heard, and whose are silenced? What are the roles of money, power, and privilege in creating, publishing, and disseminating research? What mechanisms are in place to encourage research integrity? Can users discern the accuracy of the information they access? What is the role of the library in assisting users in developing needed critical evaluation competence? To fully achieve the mission of article 19, users must have access to information and the critical evaluation skills to consider and use it effectively.

Open access (OA) initiatives sought to provide the inclusion of all voices in essential issues. Suber (2012) explains that OA addresses many of the problems of access presented by traditional journal publishing mechanisms. Traditional publishing models can shut individuals without access to institutional subscriptions or the money to pay for individual subscriptions out of the scholarly conversation. Kuklinski, Quirk, Jerit, Schwieder, \& Rich (2000) argue that citizens must have "access to factual information" (p. 791) and the ability to use these facts to evaluate public policy and inform their preferences. Access to information is necessary for people to engage in the functioning of modern society.

Access to scholarship is essential for development, as researchers need to participate in scientific progress; however, OA may privilege organizations and voices that have the most power, money, and access, while marginalizing researchers unable to afford to enter the conversation. Journal page charges may shut out the voices that most need to be heard. Corporations can seed the literature with disinformation by using journal supplements, lower-quality journals, or even journals explicitly created to promote corporate designed science (Eriksson \& Helgesson, 2017; Grant, 2009). The issue of equity is highlighted in the 2019 Open Access Week theme "Open for Whom? Equity in Open Knowledge.” (Open Access Week, 2019). Open Access can be a way to increase access to information for readers. However, this increased access to information can be a double-edged sword, presenting as many challenges as solutions. Industry-sponsored misinformation is rampant, and information professionals need to help empower users to exercise their agency.

\section{The need for information literacy}

As technology has grown more complex, information seekers have been able to access an unlimited quantity of information on the Internet. Despite the abundance of available information, decision making has not improved; instead, this increased information has led to problems including bias, disinformation, misinformation, and the rise of "fake news." Information abundance has revealed the essential importance of critical information literacy.

Information seekers can find an abundance of information on any topic; however, the reader may not have the necessary tools to critically evaluate the material and seek evidence to support wise decision making. Sturges and Gastinger (2010) argue that information literacy is a human right essential for the "effective exercise of intellectual freedom" (p. 195). Without information literacy, users can access information; however, they may be unable to effectively use the information to make the best choices to meet their needs. Users may access information that is inaccurate and created to misinform. Information literacy enables users to begin to develop a critical response to information (Sturges \& Gastinger, 2010). Sturges and Gastinger (2010) explain that that information literacy is required for lifelong learning and is a prerequisite for participation in a complex information society. Developing information literacy requires a user to acquire a set of competencies that an informed citizen ought to possess to participate intelligently 
and actively in the world (Sturges \& Gastinger, 2010). Even when information is widely available, it can be inaccurate or intentionally misleading (Saunders, 2013).

Misinformation, disinformation, and propaganda are techniques used by governments, corporations, and ideological groups to sway opinion and encourage action (Saunders, 2013). Information is not only recognized as a tool for education and edification but also as a cudgel that can be wielded for ill. Institutions with money, power, and influence can create information that shapes the narrative to benefit commercial, ideological, and political purposes.

\section{The Impact of Funding Source}

After decades of the government funding the bulk of the scientific research in the United States, the balance has shifted, and now most research funding comes from private sources (Washburn, 2007). Although relevant research must receive funding, the source of research funding can have significant effects on the research done (Krimsky, 2010). Shamoo and Resnick (2009) found that relationships between industry and researchers can have an impact on questions asked, methodology employed, results presented, and conclusions reached. Many large industries, including tobacco, food, pharmaceuticals, chemicals, and energy, have funded studies that shape the narrative, sway public opinion, avoid regulation, and inform public policy.

This corporate shaping of the narrative can be a serious problem because research has found that once an erroneous belief has been established, it can be difficult to correct, even when accurate alternative information is provided (Nyhan \& Reifler, 2010). There has even been a "backfire effect" observed; when presented with opposing information, the erroneous belief will be strengthened, rather than corrected (Nyhan \& Reifler, 2010). The research also finds that inaccurate information persists even after retraction and continues to be cited (Budd, Coble \& Anderson, 2011). Retractions are often separated from the original publication, so a reader may not be aware of the retraction. However, some online publishers stamp "Retracted" on the electronic text of the article this practice is not universal.

Concerns about the dissemination of inaccurate information are not universal. Supporters of OA suggest that the benefits of more accessible research outweigh the disadvantages. Suber (2012) states, "[i]f we are really concerned about online dreck, we should dilute it with high-quality research rather than leave the dreck unchallenged and uncorrected" (p. 118). Unfortunately, inaccurate information can be like poison; there is no amount of dilution that can make it safe. There are many examples of corporate-funded information having a detrimental impact on human health, the environment, and the creation of public policy.

\section{The problem of industry misinformation}

The most well-known example of corporate manufacture of research contributing to disinformation is seen in the tobacco industry (for more see Brandt, 2012). When the evidence implicated tobacco as the cause of disease in the 1950's, and 1960's the tobacco industry recruited scientists to produce research to cast doubt on studies linking tobacco to harm (Brandt, 2012). The tobacco industry tried to distance itself from the research by funding front groups to fund research and block legislation and regulation (Apollonio \& Bero, 2007). According to Brandt (2012), this invention of controversy "undermines the notion of the common good" (p. 70). The tobacco industry continues its campaign of misinformation in developing nations around the world where the governments lack the resources to counter the tobacco industry and where the populace is left with the legacy of disease, disability, and death (Mackay \& Crofton, 1996). While the denial tactics of the tobacco industry have been well documented and are well recognized by the public, the denial tactics of the food industry are less well known but echo the tactics used by the tobacco industry (Capewell \& Lloyd-Williams, 2018).

Unfortunately, the techniques perfected by the tobacco industry did not stop with the tobacco industry but continue to exist to this day. The sugar industry "funded studies that downplayed, ignored, or 
discredited research that found that sugar was a contributor to heart disease" (Krimsky, 2017, p. 124). Despite evidence to the contrary, the sugar industry hired researchers who shifted the blame for cardiovascular disease from sugar to dietary fat (O'Connor, 2016). As excessive sugars, especially in the form of sugarsweetened beverages, were implicated in the rise of obesity, the sugar industry and their front groups, such as the International Life Sciences Institute (ILSI) funded research and symposia to cast doubt on sugars relationship with obesity (Blackburn \& Walker, 2005). Capewell and Lloyd-Williams (2018) explain that the techniques of the food industry are examples of corporate political activity (CPA). These CPA techniques employ denialism, which Diethelm and McKee (2019) define as "using rhetorical arguments to give the appearance off legitimate debate where there is none, with the ultimate goal of rejecting a proposition on which a scientific consensus exists" (p.2). The exercise of denialism is not limited to use in the food industry; rather, it is utilized by many industries.

In addition to the food industry, the pharmaceutical industry has numerous examples of industryfunded promotion of flawed studies. Pharmaceutical companies have disseminated information to suggest that their drugs were safer and more efficacious than the research demonstrated. They are incentivized to find favorable results, but this is fraught with the potential for conflicts of interest. There can be motivation to design studies that will provide support for the corporate viewpoint. There are too many examples of flawed pharmaceutical studies to list them all, but a few examples show the far-reaching consequences of this conflicted information. The Vioxx case is one example of where the withholding of negative data caused tremendous harm. Vioxx was a pain reliever promoted to be superior to others on the market, with less bleeding risk (Washburn, 2007). It was later discovered that Merck, the manufacturer of Vioxx, intentionally withheld evidence that Vioxx increased the risk of heart attack, stroke, and death (Curfman, Morrissey \& Drazen, 2005). It is estimated that 139,000 excess heart attacks occurred as a result of taking Vioxx (Washburn, 2007).

Similarly, the antidepressant Paxil was judged to be safe and effective. It was later revealed that data indicating that Paxil increased suicidality in pediatric patients had not been disclosed (Giles, 2008). Later it was discovered that Paxil was neither safe nor effective in pediatric patients, yet it had been a lucrative drug for GlaxoSmithKline (Carey, 2015). Sadly, these are only two of numerous examples of flawed pharmaceutical research.

While the previous examples relate to human health, the impact is not isolated to these research areas. Public perception of climate change has been another issue where industry funding has created research to support the industry's position. The petroleum industry denial of climate change has involved a wellfinanced operation to create doubt in the mind of the public about the role of human activity in climate change (Brulle, 2014). Investigators have found that Exxon hid evidence of climate change for decades (Breslow, 2015). Several front groups were formed to promote research on climate change from the industry's point of view (Brulle, 2014). Unlike the tobacco and pharmaceutical industries, climate contrarians have not had as much success having their research published in peer-reviewed journals; most of it is published by think tanks (Dunlap \& Jacques, 2013). Budd (2007) examined the politicization of the research around climate change, finding that claims about climate change were shaped more by ideology than by science. Budd (2007) explains, "Ideology, as the foundation for beliefs, may or may not include veritism as a substantive reason for belief” (p. 2371). While policymakers should consider scientific evidence in the construction of public policy, on the issue of climate change, this is not always the case.

Another example is the case of fire retardants. To thwart calls for self-extinguishing cigarettes to prevent house fires, the tobacco industry encouraged the use of flame-retardant chemicals in clothing and furniture (Callahan \& Roe, 2012). Regulations mandate that clothing and furniture meet flammability standards, even though many flame-retardant chemicals are known carcinogens (Abel, 2016). Many firefighters are being diagnosed with cancer and dying likely due to these chemicals, yet the industry continues to fight the science (Abel, 2016).

While these examples are well known, there are many more that are less well known. Without a full understanding of the impact of conflict of interest on the body of research, the existence of disinformation can continue to cause harm. Right now, the United States is facing two major health crises fueled by disinformation. The opioid epidemic began in the late 1990s with a flawed letter that suggested that opioids 
were rarely addictive (Hawkins, 2017); this was cited thousands of times. Misleading research coupled with the relentless promotion of the new longer-acting formulations and a new culture of aggressive treatment of pain, encouraged by the pharmaceutical industry, spurred a public health crisis that currently takes approximately 70,000 (CDC, 2019) lives each year. Although the history of the tobacco industry's manipulation of information is well known, the industry promoted vaping to quit smoking. The promotion of vaping seems to be following the same disinformation techniques as the promotion of smoking. While vaping was promoted for current smokers to transition away from tobacco, many young people initiated nicotine use (Iacobucci, 2019). In the summer of 2019, as vaping related illness and deaths dominated the news, the vape manufacturer Juul was running daily ads on the digital edition of the New York Times touting the responsibility of the company in preventing youth vaping. The data does not bear this out (Iacobucci, 2019), as youth vaping has doubled in recent years. Society needs access to accurate information to make wise decisions in designing public policy. Readers need to have the skills to question information presented to them to determine if it is worthy of belief.

\section{Industry disinformation tactics}

Tobacco, alcohol, food, and drink industries are responsible for millions of deaths each year and are the top factors in the global disease burden (Moodie, Stuckler, Monteiro, Sheron, Neal, Thamarangsi, \& Lancet NCD Action Group, 2013). Moodie et al. (2013) found that there are four strategies that these corporations use to disinform the public. "The first strategy is to bias research findings" (Moodie et al., 2013, p. 673). "The second strategy is to co-opt policymakers and health professionals" (Moodie et al., 2013, p. 673). "The third strategy is to lobby politicians and public policy officials to oppose public regulations" (Moodie et al., 2013, p. 674). The fourth strategy is to encourage voters to oppose public health regulations (Moodie et al., 2013, p. 674). While Moodie et al. (2013) researched tobacco, alcohol, and food, these techniques can be seen in many other industries as well.

Savell. Gilmore and Fooks (2014) reviewed the literature for the arguments and tactics used by the tobacco industry to influence marketing activities. Savell et al. (2014) found that these examples of Corporate Political Activity (CPA) fell into four categories, including unintended negative consequences, legal arguments, regulatory redundancy, and insufficient evidence. These four techniques can be seen today in many industries, notably in current discussions around opioids and vaping. Information seekers should be aware of the techniques employed to confuse them so that users can develop strategies to combat CPA.

\section{The role of the library}

A library does not create an engaged populace by its mere existence; it needs to ensure that people have the skills to become actively engaged with ideas and capable of critical evaluation of the information they encounter. Unfortunately, just because something comes from the library or accessed from a database, it does not mean that the information has been thoroughly vetted (Sullivan, 2019). Information consumers need to be aware that not all information is accurate, credible, or worthy of belief. Without information literacy, access to vast amounts of information could confuse or deceive the reader (Sturges \& Gastinger, 2010). LIS professionals should engage with the question of the importance of an informed citizenry for a functioning democracy (Sullivan, 2019). Libraries need to create structures that empower their users to actively engage with information and develop a critical stance. Merely providing access to information is not enough.

Despite knowledge of industry influence in science, readers may not be able to exercise the level of scrutiny that is warranted considering the history of conflicts of interest (COI). Industry-funded studies are not always easy to recognize. The growth of $\mathrm{OA}$ titles has made it more challenging for users to determine which journals may be worthy of trust. While some industry-funded studies are published by journals, others are published as journal supplements or placed directly on the web by organizations. Many times, 
industry-funded studies will promote promising findings in press releases. John Bohannon studied just how easy it was to publish and promote a fake, but appealing study (Godoy, 2015). Companies are interested in convincing people to purchase their products, so highlighting product benefits can benefit the company's bottom line. Librarians can assist users in making choices that align with their needs and interests while assisting users in finding accurate evidence. There are many ways in which librarians can assist users in engaging with and evaluating information.

While there has been a large body of literature about libraries' response to the "Fake News" phenomena following the 2016 election (Cooke, 2017), the issue of corporate sponsorship of research has been less well covered in the LIS literature. Librarians interested in learning more about the impact of COI on studies can begin by familiarizing themselves with the breadth of studies it impacts. McIntyre (2018) explores the many facets of this issue in Post-Truth. Investigative journalism organizations ProPublica (Propublica.org, 2019) and Tarbell (Tarbell.org, 2019) have many stories that cover the intersection of money and research findings. Tarbell.org discusses the issue and has been collecting a database of industry-funded studies at \#industryfunded (Rettino, 2018). ProPublica and Tarbell are accessible sources to help users become familiar with the issue. The New York Times and Washington Post also cover many stories of corporate influence on research, and one can set us an RSS feed to keep up with these articles.

\section{Role of librarians}

Today's users are faced with a complex information landscape, where information is easy to locate but difficult to evaluate and use effectively. Librarians can encourage users not to seek the "right answer" but to ask questions and interrogate the power structures underlying the creation of information sources. Proponents of critical information literacy (IL) urge librarians to rethink their practice to move from skills acquisition to creating inquisitive users who question their information sources. (Cope, 2017). Critical IL instruction enables librarians to align their practice with the democratic values they espouse.

Critical IL argues that librarianship must evolve beyond supporting the status quo and the commercial and political structures that narrow the options of users. Gage argues that librarians should support users as "critical and engaged citizens capable of materializing the possibilities of collective agency and democratic life" (in Elmborg, 2006, p. 193). For users to exercise their agency, they must be able to reveal the underlying power structures within the creation, publication, and dissemination of information sources and actively evaluate the sources to be able to make informed choices in their best interests. The individual exercise of their agency is essential in today's world as political and industrial structures use misinformation and disinformation to encourage citizens to make decisions that are contrary to their best interests. Without viewing information through a critical lens, a reader could accept this disinformation without recognizing the underlying rationale for its creation. Industry-funded misinformation and disinformation disproportionately impact the young, the poor, and the powerless while privileging the status quo and benefiting those with wealth, status, and power. Critical IL empowers citizens to seek information that meets their needs and enables them to call out politicians making decisions that would adversely impact them. Advocates of critical information literacy encourage students to actively engage with information in order to develop their critical consciousness and enable then to exercise their agency to better their own lives.

Librarians are challenged to communicate information about the influence of external information on the information that their users' access. Capewell and Lloyd-Williams (2018) explain that advocacy and activism are essential to counter CPA efforts; they created an easy acronym, MARSH, to help people remember the tactics that industry uses to inform. MARSH stands for misinform, attack, recruit, substitute, and heap. Misinform refers to corporate attempts to reshape evidence and create doubt. Attack refers to efforts to discredit and neutralize opponents. Recruit involves the building of internal and external constituencies to support the corporate viewpoint. Substitute is a strategy where corporations suggest ineffective interventions or voluntary regulations to thwart more effective solutions. Finally, Heap refers to the money that is distributed to politicians and researchers (Capewell \& Lloyd-Williams, 2018). Cultivating an attitude of informed skepticism can reduce vulnerability to misinformation (Lewandowsky et al., 2005). 
There are many tools and strategies that librarians can use to help users develop and exercise informed skepticism. The Union of Concerned Scientists created a Disinformation Playbook (Union of Concerned Scientists, 2019) to articulate the techniques used to disinform the public. The podcast and National Public Radio program On the Media has created Consumer Handbooks to assist users in becoming critical consumers of information (On the Media, 2019). Understanding the techniques of industry can help users protect themselves from becoming disinformed.

One of the techniques that corporations have successfully used to disinform users is denialism, recognizing the features of denialism may assist users in understanding and rejecting it. Denialism is the rejection of the consensus of scientific evidence on a topic, and the embrace of individual dissenting voices. Denialism can exploit genuine concerns, especially where there is a history of mistrust (Diethelm \& McKee, 2009). Still, those exercising denialism are often doing it for their purposes, rather than protecting others. Diethelm and McKee (2009) explain the five characteristics of denialism: conspiracy, fake experts, selectivity, impossible expectations, and misrepresentation. These five techniques are used alone or in combination to cast doubt on the science. The first characteristic is conspiracy; when the body of scientific opinion indicates that something is true, it is not because the evidence points in this direction. Rather, the conspiracy theorist believes there is an elaborate conspiracy hiding the truth (Diethelm \& McKee, 2009). An example of conspiracy can be seen in vaccine denialism. The second technique, fake experts, is the one which uses researchers who purport to be experts, yet do not align with current understanding of the issue (Diethelm \& McKee, 2009). The technique of fake experts was seen in the tobacco industry and is seen in climate denial. The third characteristic, selectivity, where isolated papers that challenge the dominant viewpoint are held in high esteem, even when they are not deserving of esteem (Diethelm \& McKee, 2009). The fourth characteristic is the creation of impossible expectations; the level of evidence demanded is not attainable (Diethelm \& McKee, 2009). The fifth technique is the "use of misrepresentation and logical fallacies" (Diethelm \& McKee, 2009, p. 3). Users should be aware of the features of denialism and recognize that they are motivated by money, ideology, faith, and eccentricity (Diethelm \& McKee, 2009).

Another way in which a librarian can help patrons resist disinformation is by assisting them in asking good questions about the information they are accessing. Hatch (2018) provides some key questions to consider when examining research. One should evaluate whether the conclusions make sense given the data presented. Users should look for effusive praise, and outrageous claims, as these can be signs of research created to promote a product or position. Hatch (2018) also suggests that readers consider whether a research study serves an external purpose, such as creating doubt or thwarting regulations. Librarians can also talk to users about challenges to information integrity and the limitations to the library's ability to curate information. Librarians should explain to users that just because something is in a library, a commercial database, or on the internet, it does not mean that it has been validated for accuracy. Librarians should help users to understand that information sources are created for a wide variety of reasons, and that all sources may not be appropriate for every information need.

Librarians can inform their practice to create institutions that provide unfettered access to information while assisting patrons in developing the cognitive skills to fight disinformation. One way librarians can assist patrons is by becoming better informed themselves. Industry-funded studies can be challenging to recognize, so librarians need to become well informed to recognize the signs that raise red flags. Of course, simply being funded by industry is not a rationale for disregarding excellent research. However, one should exercise caution and make sure that the research upon which one is basing decisions is worthy of that trust. Another way that librarians can support access, coupled with supporting the development of evaluation skills, is through creating collections that are inclusive but do not misrepresent the scale of an argument for the sake of balance.

Additionally, librarians can question how the library deals with inaccurate information and evaluate whether this is the right approach for their community. Finally, Librarians can support projects that seek to make information more open and transparent, such as the Center for Open Science. Librarians can use their combined influence to push journals for stronger disclosure and peer review practices. They can also encourage database providers to provide funding information. Pubmed and Web of Science have begun to offer this information; more platforms should join them. 


\section{Conclusion}

OA has provided enormous opportunities for expanding the marketplace of ideas and including voices that have previously been unheard. Unfortunately, entities with power and money can dominate the conversation, requiring information seekers to be critical consumers of information. Users need to acquire the skills to effectively evaluate information before adding it to their knowledge base, as some information is not worthy of belief. The phenomena of "fake news" illustrates the pernicious implications of believing inaccurate information. Sullivan (2019) argues that what librarians have been doing in the fight against "fake news" is not enough. Recognizing the real dangers that misinformation presents, Sullivan (2019) explains that librarians must "reengage rather than simply reaffirm some of their core values specifically the tension between providing unrestricted access and 'providing epistemological protection'” (Walsh, 2018, p. 498, cited in Sullivan, 2019). The myriad ways in which information is disseminated creates confusion and can privilege some voices over others. While some viewpoints are actively censored, others are crowded out by industry or ideological narrative. Industrial and ideological organizations have the funding and the infrastructure, dating back to the tobacco industry era, to effectively disseminate disinformation. Historically underrepresented groups and developing nations do not have the financial resources to compete. Controversy can be manufactured in areas in which no controversy exists. A reader may not have the tools to critically evaluate the material and seek evidence. Sturges and Gastinger (2010) argue that information literacy is a human right essential for the "effective exercise of intellectual freedom." Martha Allen (2019) explains this by adapting Bryan Stevenson's (2012) "[t]he opposite of poverty is not wealth. It is justice." Allen (2019) says, "the opposite of information poverty is social justice information literacy instruction."

While access to information is essential, it is insufficient to create an informed, engaged populace. Information literacy is necessary for users to think critically and analytically about evidence and make the right decisions for their purposes. While governments use misinformation and propaganda to promote their agenda, their actions are often called out by the press. However, this is not usually the case with industry use of misinformation; industry is often not revealed to have used misinformation until long after the damage has been done. Until users are empowered with the skills to effectively use and evaluate information, the promise of Article 19 will not be fulfilled.

\section{References}

Abel, D. (2016, April 24). Mass firefighters seek ban on flame retardants. The Boston Globe. Retrieved from https://www. bostonglobe.com/metro/2016/04/24/firefighters-seek-new-law-ban-flame-retardants/Zzv8aVoRN6WTcpKDIvV4cP/ story.html

Allen, M. (2019). Email correspondence.

Apollonio, D. E., \& Bero, L. A. (2007). The creation of industry front groups: The tobacco industry and "get government off our back". American Journal of Public Health, 97(3), 419-427. https://doi.org/10.2105/AJPH.2005.081117

Blackburn, G. L., \& Walker, W. A. (2005). Science-based solutions to obesity: What are the roles of academia, government, industry, and health care? The American Journal of Clinical Nutrition, 82(1, Suppl), 207S-210S. https://doi.org/10.1093/ ajcn/82.1.207S

Brandt, A. M. (2012). Inventing conflicts of interest: A history of tobacco industry tactics. American Journal of Public Health, 102(1), 63-71. https://doi.org/10.2105/AJPH.2011.300292

Breslow, J. M. (2015, September 16) Investigation finds Exxon ignored its own early climate change warnings. PBS Frontline. Retrieved from http://www.pbs.org/wgbh/frontline/article/investigation-finds-exxon-ignored-its-own-early-climatechange-warnings/

Brulle, R. J. (2014). Institutionalizing delay: Foundation funding and the creation of U.S. climate change counter-movement organizations. Climatic Change, 122(4), 681-694. https://doi.org/10.1007/s10584-013-1018-7

Budd, J. M. (2007). Information, analysis and ideology: A case study of science and the public interest. Journal of the American Society for Information Science and Technology, 58(14), 2366-2371. https://doi.org/10.1002/asi.20703

Budd, J. M., Coble, Z. C., \& Anderson, K. M. (2011, March). Retracted publications in biomedicine: Cause for concern. In Association of College and Research Libraries Conference (pp. 390-5). 
Callahan, P., \& Roe, S. (2012, May 8). Big Tobacco wins fire marshals as allies in flame retardant push. Chicago Tribune. Retrieved from http://www.chicagotribune.com/ct-met-flames-tobacco-20120508-story.html

Capewell, S., \& Lloyd-Williams, F. (2018). The role of the food industry in health: Lessons from tobacco? British Medical Bulletin, 125(1), 131-143. https://doi.org/10.1093/bmb/ldy002

Carey, B. (2015, September 17). Antidepressant Paxil is unsafe for teenagers, new analysis says. The New York Times, A20.

Centers for Disease Control. (2019). Drug overdose deaths. CDC. Retrieved from https://www.cdc.gov/drugoverdose/data/ statedeaths.html

Cooke, N. A. (2017). Posttruth, truthiness, and alternative facts: Information behavior and critical information consumption for a new age. The Library Quarterly, 87(3), 211-221. https://doi.org/10.1086/692298

Cope, J. T. (2017). The reconquista student: critical information literacy, civics, and confronting student intolerance. Communications in Information Literacy, 11(2), 2, 264-282.

Curfman, G. D., Morrissey, S., \& Drazen, J. M. (2005). Expression of concern: Bombardier et al., "Comparison of upper gastrointestinal toxicity of rofecoxib and naproxen in patients with rheumatoid arthritis," N Engl J Med 2000;343:1520-8. The New England Journal of Medicine, 353(26), 2813-2814. https://doi.org/10.1056/NEJMe058314

Diethelm, P., \& McKee, M. (2009). Denialism: What is it and how should scientists respond? European Journal of Public Health, 19(1), 2-4. https://doi.org/10.1093/eurpub/ckn139

Dunlap, R. E., \& Jacques, P. J. (2013). Climate change denial books and conservative think tanks: Exploring the connection. The American Behavioral Scientist, 57(6), 699-731. https://doi.org/10.1177/0002764213477096

Elmborg, J. (2006). Critical information literacy: Implications for instructional practice. Journal of Academic Librarianship, 32(2), 192-199. https://doi.org/10.1016/j.acalib.2005.12.004

Eriksson, S., \& Helgesson, G. (2017). The false academy: Predatory publishing in science and bioethics. Medicine, Health Care, and Philosophy, 20(2), 163-170. https://doi.org/10.1007/s11019-016-9740-3

Giles, J. (2008). Did GlaxoSmithKline trial data mask Paxil suicide risk? New Scientist, 197(2642), 12. https://doi.org/10.1016/ S0262-4079(08)60322-X

Godoy, M. (2015). Why A Journalist Scammed The Media Into Spreading Bad Chocolate Science. The Salt. https://www.npr.org/ sections/thesalt/2015/05/28/410313446/why-a-journalist-scammed-the-media-into-spreading-bad-chocolate-science

Grant, B. (2009). Elsevier published 6 fake journals. Scientist (Philadelphia, Pa.), 7(5).

Hatch, D. (2018) Industry funded studies and the skewing of America Tarbel Investigations. https://tarbell.org/2018/04/ industry-funded-studies-and-the-skewing-of-america/

Hawkins, D. (2017 June 2). How a Short Letter in a Prestigious Journal Contributed To the Opioid Crisis The Washingon Post. Retreived from https://www.washingtonpost.com/news/morning-mix/wp/2017/06/02/how-the-opioid-crisis-tracesback-to-a-five-sentence-scholarly-letter-from-1980/

lacobucci, G. (2019). Vaping among US teens has doubled since 2017. BMJ (Clinical Research Ed.), 366, 15653. https://doi. org $/ 10.1136 /$ bmj. 15653

Krimsky, S. (2010). Combating the funding effect in science: What's beyond transparency. Stanford Law \& Policy Review, 21, 81-123.

Krimsky, S. (2017). Sugar Industry Science and Heart Disease. Accountability in Research, 24(2), 124-125. https://doi.org/10.1 080/08989621.2016.1244767

Kuklinski, J. H., Quirk, P. J., Jerit, J., Schwieder, D., \& Rich, R. F. (2000). Misinformation and the currency of democratic citizenship. The Journal of Politics, 62(3), 790-816. https://doi.org/10.1111/0022-3816.00033

Lewandowsky, S., Stritzke, W. G., Oberauer, K., \& Morales, M. (2005). Memory for fact, fiction, and misinformation: The Iraq War 2003. Psychological Science, 16(3), 190-195. https://doi.org/10.1111/j.0956-7976.2005.00802.x

Mackay, J., \& Crofton, J. (1996). Tobacco and the developing world. British Medical Bulletin, 52(1), 206-221. https://doi. org/10.1093/oxfordjournals.bmb.a011527

McIntyre, L. (2018). Post-truth. Cambridge, MA: MIT Press. https://doi.org/10.7551/mitpress/11483.001.0001

Moodie, R., Stuckler, D., Monteiro, C., Sheron, N., Neal, B., Thamarangsi, T., . . Casswell, S., \& the Lancet NCD Action Group. (2013). Profits and pandemics: Prevention of harmful effects of tobacco, alcohol, and ultra-processed food and drink industries. Lancet, 381(9867), 670-679. https://doi.org/10.1016/S0140-6736(12)62089-3

Nyhan, B., \& Reifler, J. (2010). When corrections fail: The persistence of political misperceptions. Political Behavior, 32(2), 303-330. https://doi.org/10.1007/s11109-010-9112-2

O'Connor, A. (2016, September 12). How the sugar industry shifted the blame to fat. The New York Times. Retrieved from http://www.nytimes.com/2016/09/13/well/eat/how-the-sugar-industry-shifted-blame-to-fat.html

On the Media (2019) On the Media's breaking news consumer's handbooks. WNYC. Retrieved from https://www.wnycstudios. org/podcasts/otm/projects/breaking-news-consumers-handbook

Open Access Week (2019). Open Access Week 2019. International Open Access Week. Retrieved from http://www.openaccessweek.org/

ProPublica (2019). https://www.propublica.org/

Rettino, J. (2018). Big Industries skewing science: What you can do. Tarbel Solutions. https://tarbell.org/solutions/industryfunded-studies-what-you-can-do/?ref=feed 
Saunders, L. (2013, April). Information as weapon: Propaganda, politics, and the role of the library. In Imagine, Innovate, Inspire: The Proceedings of the ACRL 2013 Conference (Vol. 4, pp. 309-318).

Savell, E., Gilmore, A. B., \& Fooks, G. (2014). How does the tobacco industry attempt to influence marketing regulations? A systematic review. PLoS One, 9(2), e87389. https://doi.org/10.1371/journal.pone.0087389

Shamoo, A. E., \& Resnik, D. B. (2009). Responsible conduct of research. Oxford, England: Oxford University Press. https://doi. org/10.1093/acprof:oso/9780195368246.001.0001

SPARC (2019). Open Access. Scholarly Publishing and Academic Resources Coalition. https://sparcopen.org/open-access/

Stevenson, B. (2012). We need to talk about an injustice. TED2012. Retrieved from https://www.ted.com/talks/bryan_ stevenson_we_need_to_talk_about_an_injustice/transcript?language $=e n$

Sturges, P., \& Gastinger, A. (2010). Information literacy as a human right. Libri, 60(3), 195-202. https://doi.org/10.1515/ libr. 2010.017

Suber, P. (2012). Open Access. Cambridge, MA: MIT Press. https://doi.org/10.7551/mitpress/9286.001.0001

Sullivan, M. C. (2019). Libraries and Fake News: What's the Problem? What's the Plan? Communications in Information Literacy, 13(1), 91-113. https://doi.org/10.15760/comminfolit.2019.13.1.7

Tarbel.org. (2019). Industry funded studies and the skewing of America. Tarbel Investigations. Retrieved from https://tarbell. org/project/industry-funded-studies-and-the-skewing-of-america/

Union of concerned scientists. (2018). The disinformation playbook. Retrieved from https://www.ucsusa.org/resources/ disinformation-playbook

United Nations (2018). Universal declaration of human rights. Retrieved from https://www.un.org/en/universal-declarationhuman-rights/

Washburn, J. (2007). Science under siege. Discover, 28(10), 66-73. 